\title{
POLÍTICAS PÚBLICAS PARA AGRICULTURA FAMILIAR: O ACESSO AOS MERCADOS INSTITUCIONAIS NO ASSENTAMENTO DOM JOSÉ MAURO EM UBERLÂNDIA (MG)1
}

\author{
Alessandra Rodrigues GUIMARÃES ${ }^{2}$ \\ José Giacomo BACCARIN3
}

\begin{abstract}
RESUMO
O município de Uberlândia (MG) possui significativa relevância para o agronegócio nacional, mas, mesmo possuindo grande destaque neste segmento, são registrados números elevados de ocupação e manifestações de luta pela terra. É um dos municípios com o maior número de assentamentos rurais do Triângulo Mineiro/Alto Paranaíba, totalizando 15 assentamentos. As famílias assentadas representam grande importância na produção de alimentos no município por fornecerem os alimentos via Programa Nacional de Alimentação Escolar e Programa de Aquisição de Alimentos. O objetivo desta pesquisa é analisar a efetividade das políticas públicas no assentamento Dom José Mauro, com o intuito de verificar se as famílias conseguem permanecer em suas terras e continuarem produzindo em seus lotes. Esta pesquisa justifica-se por tratar-se de uma temática inserida em um contexto não apenas local ou regional, mas nacional, que é a (re) produção da agricultura familiar.
\end{abstract}

Palavras-chave: Assentamentos rurais. PNAE. PAA. Políticas Públicas. Uberlândia (MG).

\section{PUBLIC POLICIES FOR FAMILY AGRICULTURE: ACCESS TO INSTITUTIONAL MARKETS IN THE DOM JOSÉ MAURO SETTLEMENT IN UBERLÂNDIA (MG)}

\begin{abstract}
The municipality of Uberlândia (MG) has significant relevance for national agribusiness, but, despite having great prominence in this segment, high numbers of occupation and manifestations of struggle for land are registered. It is one of the municipalities with the largest number of rural settlements in the Triângulo Mineiro / Alto Paranaíba, totaling 15 settlements. Settled families represent great importance in the production of food in the municipality for

\footnotetext{
${ }^{1}$ Este texto é parte da Tese de Doutorado intitulada: "O PAPEL DAS POLÍTICAS PÚBLICAS NA RESISTÊNCIA DOS ASSENTAMENTOS RURAIS: o PA Dom José Mauro em Uberlândia (MG)", ainda em desenvolvimento no Programa de Pós-Graduação em Geografia da Universidade Estadual Paulista "Júlio de Mesquita Filho" / Campus Rio Claro (SP).

2 Doutoranda no Programa de Pós-Graduação em Geografia da Universidade Estadual Paulista "Júlio de Mesquita Filho" - UNESP/ Rio Claro (SP) - E-mail: alessandraufu@gmail.com

3 Professor no Programa de Pós-Graduação em Geografia da Universidade Estadual Paulista "Júlio de Mesquita Filho" - UNESP/ Rio Claro (SP) - E-mail: jose.baccarin@unesp.br
} 
providing food through the National School Feeding Program and the Food Acquisition Program. The objective of this research is to analyze the effectiveness of public policies in the Dom José Mauro settlement, in order to verify whether families are able to remain on their land and continue to produce on their lots. This research is justified because it is a theme inserted not only in a local or regional context, but national, which is the (re) production of family farming.

Keywords: Rural settlements. PNAE. PAA. Public policy. Uberlândia (MG).

\section{POLÍTICAS PÚBLICAS PARA LA AGRICULTURA FAMILIAR: ACCESO A LOS MERCADOS INSTITUCIONALES EN EL ACUERDO DE DOM JOSÉ MAURO EN UBERLÂNDIA (MG)}

\section{RESUMEN}

La ciudad de Uberlândia (MG) tiene una relevancia significativa para los agronegocios nacionales, pero, a pesar de tener un gran protagonismo en este segmento, se registran altos números de ocupación y manifestaciones de lucha por la tierra. Es uno de los municipios con mayor número de asentamientos rurales en el Triângulo Mineiro / Alto Paranaíba, con un total de 15 asentamientos. Las familias asentadas representan una gran importancia en la producción de alimentos en el municipio para proporcionar alimentos a través del Programa Nacional de Alimentación Escolar y el Programa de Adquisición de Alimentos. El objetivo de esta investigación es analizar la efectividad de las políticas públicas en el asentamiento Dom José Mauro, para verificar si las familias pueden permanecer en sus tierras y continuar produciendo en sus lotes. Esta investigación está justificada porque es un tema insertado no solo en un contexto local o regional, sino nacional, que es la (re) producción de la agricultura familiar.

Palabras clave: Asentamientos rurales. PNAE. PAA. Políticas públicas. Uberlândia (MG).

\section{INTRODUÇÃ̃}

No Brasil, a agricultura familiar assumiu grande importância na economia, pois é a principal produtora de alimentos para abastecer as áreas urbanas, além de gerar emprego e renda na zona rural e permitir a permanência das pessoas ocupadas no campo. Mesmo possuindo funções importantes, este setor ainda necessita de mais atenção por parte do poder público, pois os agricultores familiares lidam com a falta de assistência técnica pública, o baixo valor agregado aos seus produtos e a dificuldade de comercializar os alimentos. 
Umas das alternativas encontradas pelos agricultores familiares para realizar a comercialização dos alimentos é o mercado institucional, por meio de programas governamentais que visam a compra de alimentos da produção familiar com o objetivo de proporcionar uma alimentação saudável para a população que se encontra em insegurança alimentar e nutricional.

O Programa de Aquisição de Alimentos (PAA) foi instituído pelo Artigo 19 da Lei $\mathrm{n}^{0} 10.696$ e regulamentado pelo Decreto $\mathrm{n}^{0}$. 4.772, ambos de 02 de julho de 2003. Foi a primeira política agrícola nacional para a agricultura familiar que se articula com a política de segurança alimentar e nutricional. A principal característica do PAA em relação a outras formas de compras públicas é a dispensa de licitação, com o preço de compra sendo previamente fixado e podendo o agricultor familiar participar individualmente ou através de uma associação ou cooperativa.

Outra política pública de grande importância para o meio rural é o Programa Nacional de Alimentação Escolar (PNAE), que adquire parte dos alimentos cultivados pela agricultura familiar para a alimentação escolar, que foi instituída pela Lei $\mathrm{n}^{\mathrm{0}} 11.947$, de 16 de junho de 2009 e regulamentada pela Resolução $\mathrm{n}^{0}$ 38, de 16 de julho de 2009, do Fundo Nacional de Desenvolvimento da Educação (FNDE). O PNAE tem por objetivo contribuir para o crescimento e o desenvolvimento biopsicossocial, a aprendizagem, o rendimento escolar e a formação de práticas alimentares saudáveis dos alunos.

A criação e continuidade das políticas públicas agrícolas dão sustentabilidade para que o agricultor familiar continue no campo, pois é uma alternativa encontrada por eles para venderem seus produtos e terem clientela durante todo ano. As políticas públicas são importantes para dar legitimidade ao agricultor familiar, durante muitos anos, esta categoria social ficou à parte das políticas voltadas para agricultura, com muitas reinvindicações e lutas dos movimentos sociais, a partir de 1996, o Estado definiu a primeira política pública voltada para agricultura familiar, com intuito de auxiliá-los na sua reprodução no campo.

A produção familiar possui grande importância para o município de Uberlândia (MG) (figura 1). No censo agropecuário realizado pelo Instituto 
Brasileiro de Geografia e Estatística (IBGE), em 2017, foram recenseados 2.182 estabelecimentos agropecuários onde residiam agricultores familiares, demonstrando que o município não é somente um grande produtor de commodities, também sendo considerado um grande produtor de alimentos.

Figura 1 - Localização Geográfica do município de Uberlândia (MG)

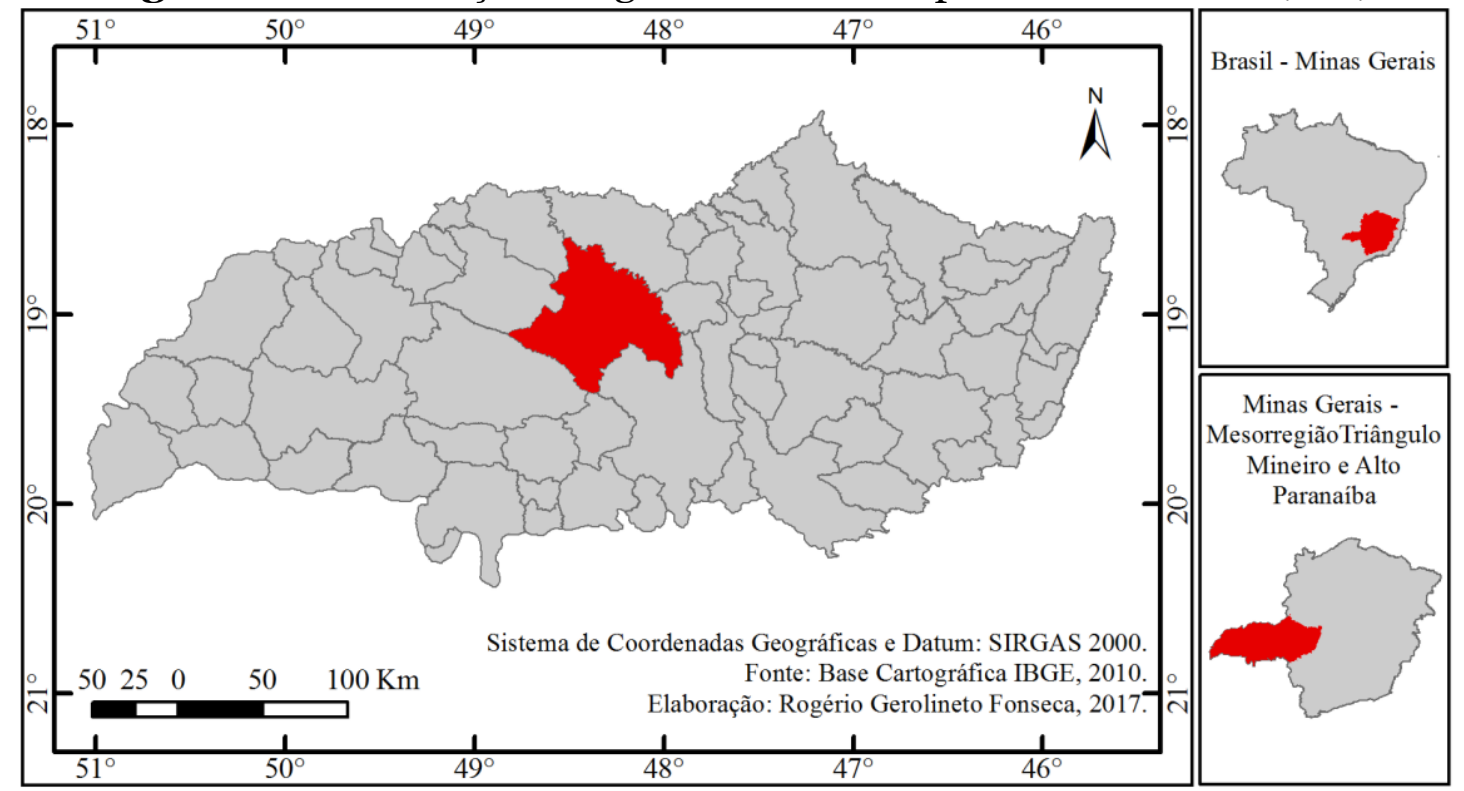

Uberlândia (MG) é um dos municípios com o maior número de assentamentos rurais do Triângulo Mineiro/Alto Paranaíba, totalizando 15 dos 87 (figura 2) existentes em toda mesorregião (INCRA, 2019). Em 1998, foi criado o primeiro projeto de assentamento de reforma agrária em Uberlândia, o PA Rio das Pedras, a partir da desapropriação de uma fazenda improdutiva. Em 1999, foram criados mais três assentamentos, os PAs Zumbi dos Palmares, Palma da Babilônia e Nova Palma. A partir de 2003, foram criados mais onze: Nova Tangará, Canudos, Flávia Nunes, Emiliano Zapata, Florestan Fernandez, José dos Anjos, Paciência, Eldorado dos Carajás, Valci dos Santos, Dom José Mauro e Celso Lúcio. 
Figura 2 - Localização dos Projetos de Assentamentos Rurais no município de Uberlândia (MG)

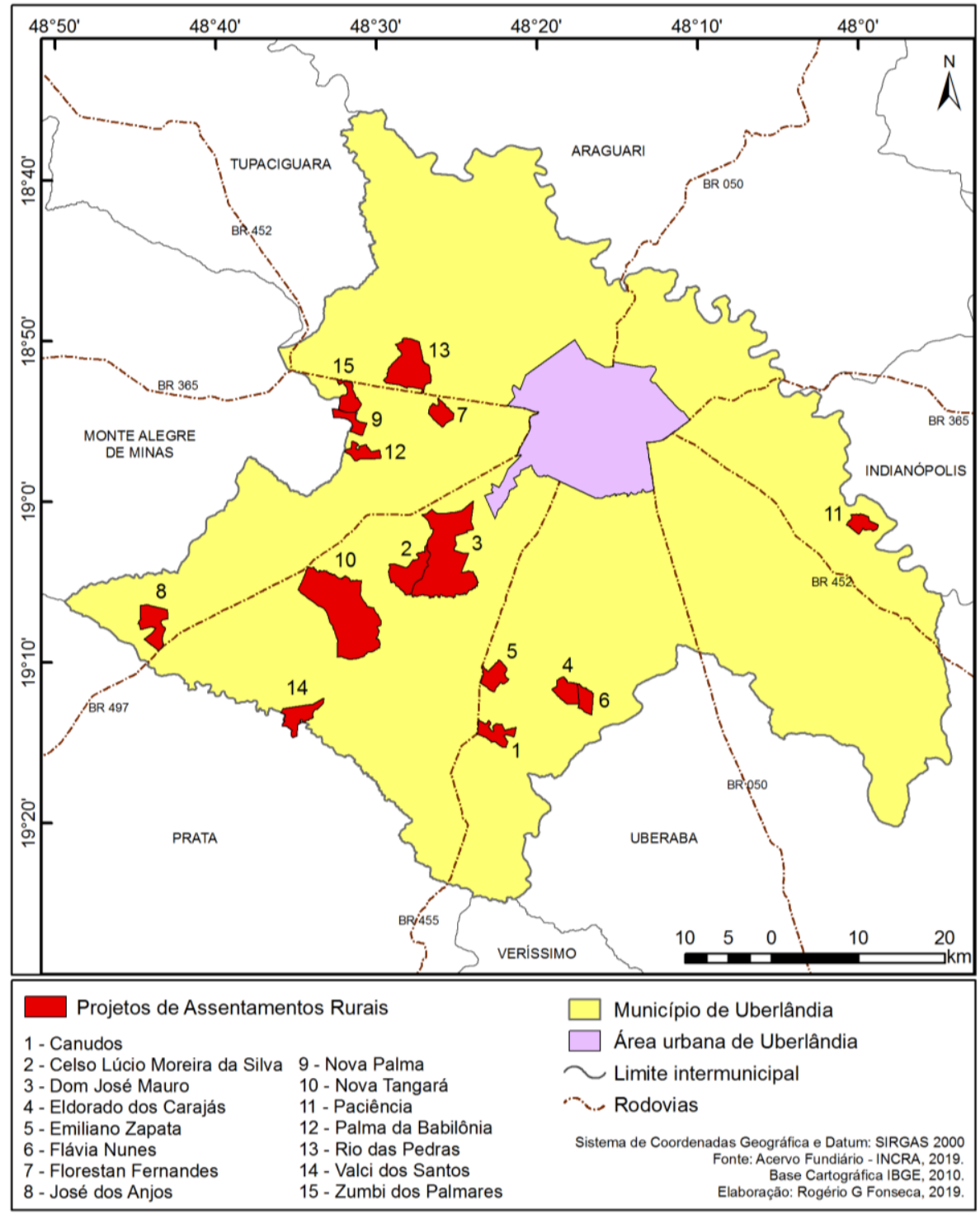

Para a realização da pesquisa, elegemos o assentamento Dom José Mauro como objeto de estudo, por ainda não possuir uma cooperativa ou associação que auxilie os assentados na comercialização dos alimentos pelos mercados institucionais e, também pelo fato de ser o segundo maior assentamento do município, possuindo 197 famílias assentadas em uma área de 4.470 hectares (ha). Para realizar a pesquisa, irão ser aplicadas entrevistas semiestruturadas em 20\% do número de famílias assentadas (40 agricultores familiares). A proposta deste estudo é analisar a efetividade das políticas públicas no assentamento rural Dom José Mauro, com o objetivo de verificar se elas 
contribuem para a permanência das famílias em seus lotes. Diante disso, defendemos a tese de que tanto o PAA, quanto o PNAE contribuem efetivamente para a permanência das famílias em seus lotes e no fortalecimento dos agricultores familiares e na estruturação de suas organizações no município de Uberlândia (MG).

$\mathrm{O}$ estudo encontra-se em desenvolvimento, nesta primeira parte da pesquisa, aplicamos entrevistas semiestruturadas com vinte famílias assentadas, correspondendo a $50 \%$ do total de entrevistados que queremos contemplar ao final da pesquisa, totalizando quarenta agricultores familiares entrevistados. Esta pesquisa visa demonstrar a importância das Políticas Públicas voltadas para agricultura familiar como meio de estimular a permanência dessas famílias no meio rural, pois um dos grandes desafios enfrentados por esses agricultores é a geração de renda e, com a participação nos programas, os agricultores familiares conseguem ter a garantia de que irão vender seus produtos e que receberão por eles.

\section{Políticas Públicas: uma breve análise}

As políticas públicas são os princípios norteadores da ação do poder público, são as diretrizes nas quais o Governo deve se orientar, fazendo relação entre a sociedade e o poder público. As políticas geralmente são formuladas com o intuito de beneficiar a sociedade, com a criação de programas, leis e linhas de financiamentos, que se orientam através de recursos públicos.

Para que um projeto seja aprovado é preciso que ele passe por diversas etapas, entre elas elaboração e implantação, não raramente cercadas de conflitos políticos, que podem dificultar sua execução. De acordo com Teixeira (2002, p. 2),

[...] as políticas públicas traduzem, no seu processo de elaboração e implantação e, sobretudo, em seus resultados, formas de exercício do poder político, envolvendo a distribuição e redistribuição de poder, o papel do conflito social nos processos de decisão, a repartição de custos e benefícios sociais. Como o poder é uma relação social que envolve vários atores com projetos e interesses diferenciados e até contraditórios, há necessidade de mediações sociais e institucionais, para que se possa obter um mínimo de consenso e, assim, as políticas públicas possam ser legitimadas e obter eficácia. 
As políticas públicas podem ter como objetivo central solucionar os problemas dos setores mais marginalizados ou vulneráveis da sociedade. Neste caso, visam ampliar e efetivar os direitos de cidadania da população, por exemplo, promovendo o desenvolvimento, criando alternativas para a geração de empregos e de renda (TEIXEIRA, 2002).

Sobre as políticas direcionadas para o setor agropecuário no Brasil, desde a década de 1960, observa-se o predomínio de um modelo de intervenção para aumentar a capacidade produtiva do setor. Nessa perspectiva, se tem como meta final melhorar a estrutura de produção para aumentar a produtividade e os rendimentos do trabalho agrícola, concedendo-se crédito rural, por exemplo. Os defensores desse modelo argumentam que ele traria aumento de renda e qualidade de vida da população rural. Mas deve ficar claro que estas políticas são agrícolas e não agrárias e que, não necessariamente, melhoram a qualidade de vida do agricultor familiar, que não detém patrimônio suficiente para conseguir empréstimos.

As políticas públicas para o setor agropecuário brasileiro foram direcionadas para a categoria de produtores mais capitalizados, por terem a capacidade de responder rapidamente aos instrumentos de intervenção utilizados pelo governo para modernizar a agricultura, criando um mercado para a indústria de máquinas, equipamentos, adubos químicos e agrotóxicos. Por isso não há tantas políticas públicas e programas direcionados para os agricultores familiares, pois diante dos "olhos" do governo, esses produtores demoram a responder às intervenções propostas para o setor agrário. A adoção de políticas de caráter produtivista provocou e ainda provoca profundas transformações na agricultura, que podem ser comparadas com outros setores da economia, consideradas mais eficientes e inovadores que o agrário.

O Governo brasileiro, em 2008, com a pressão da população cobrando programas de desenvolvimento para a sociedade, criou um catálogo de programas com Políticas Públicas destinadas para os municípios, dentre as políticas existentes, há algumas direcionadas para o desenvolvimento rural e, há um programa específico para a Assistência Técnica e Desenvolvimento Rural na Agricultura Familiar. Neste programa, o governo 
[...] visa desenvolver ações de assistência técnica, extensão rural e capacitação de agentes junto ao público da Agricultura Familiar, incluindo agricultores familiares, extrativistas, ribeirinhos, aquicultores e pescadores artesanais, indígenas e membros de comunidades remanescentes de quilombos, mulheres rurais, jovens rurais, enquadrados nos critérios estabelecidos pelo Programa Nacional de Fortalecimento da Agricultura Familiar (PRONAF); além de dirigentes, técnicos e funcionários de entidades governamentais e nãogovernamentais prestadoras de serviços de Assistência Técnica e Extensão Rural (CATÁLAGO DO GOVERNO FEDERAL, 2008, p. 42).

Diante das reivindicações que estavam sendo realizadas, uma alternativa encontrada pelo Governo foi a criação do Programa Nacional de Fortalecimento da Agricultura Familiar (PRONAF) em 1996, sendo esta política pública direcionada aos agricultores familiares, para acessarem financiamentos e auxílios para a produção e manutenção da propriedade familiar.

Além da criação do PRONAF, o Governo Federal criou e implementou duas outras políticas públicas importantes para as famílias que desenvolvem suas atividades no meio rural, o PAA e o PNAE. O PAA foi instituído no ano de 2003, com intuito de incentivar a agricultura familiar, compreendendo ações vinculadas à distribuição de produtos agropecuários para pessoas em situação de insegurança alimentar e à formação de estoques estratégicos.

Em relação ao PNAE, ele tem por objetivo contribuir para o crescimento e o desenvolvimento biopsicossocial, a aprendizagem, o rendimento escolar e a formação de práticas alimentares saudáveis dos alunos, por meio de ações de educação alimentar e nutricionais e da oferta de refeições que cubram as suas necessidades nutricionais durante o período letivo.

Estes programas do Governo Federal deram mais visibilidade para os agricultores familiares, fazendo com que eles tivessem acesso a financiamentos e auxílio técnico, além da garantia de venda dos produtos cultivados em seus lotes.

\section{Agricultura Familiar: definição e concepção}

A incorporação das terminologias "agricultura familiar", "explorações familiares”, "pequena produção rural familiar” na literatura brasileira, ocorre no final dos anos de 1980 e meados da década de 1990, procurando retratar os 
processos sociais e agrários. Uma das justificativas, é a busca de novos referenciais teóricos e analíticos que contribuam para a formação de um corpo de conceitos que extrapole os temas recorrentes, como a integração entre agricultura e a indústria e a ampliação do trabalho assalariado como sinônimo de desenvolvimento capitalista no meio rural.

Acreditando na diversidade e heterogeneidade das explorações rurais familiares, adotamos aqui, a terminologia de agricultura familiar proposta por Lamarche (1993), que se refere a uma unidade produtiva em que a família, ao mesmo tempo que trabalha, é proprietária dos meios de produção, incluindo aí vários segmentos de agricultores familiares. A esse pensamento, alia-se Wanderley (2001), que considera essa terminologia como a que melhor se aproxima e explica as heterogeneidades da produção familiar presente no espaço agrário brasileiro.

$\mathrm{O}$ agricultor familiar, em seu estabelecimento4, desenvolve as atividades agropecuárias em conjunto com sua família, produzindo produtos para o próprio consumo e comercialização no mercado. A relação existente entre família-produção-trabalho na propriedade rural familiar é fundamental para o desenvolvimento do estabelecimento, pois essa união faz com que toda a família esteja envolvida no processo de produção, resultando assim na forma como eles irão se estabelecer economicamente.

A agricultura familiar possui um papel importante para a economia brasileira e também para a sociedade, pois em seus estabelecimentos ocorre a produção de grande parte dos alimentos consumidos pelos brasileiros. $\mathrm{Na}$ agricultura familiar se obteve, em 2017, 107 bilhões de reais no valor bruto da produção agrícola brasileiro (IBGE, 2018).

A terminologia de agricultura familiar foi institucionalizada pelo governo brasileiro com a promulgação da Lei 11.326/2006, que define critérios para

\footnotetext{
4 De acordo com o IBGE, considera-se como estabelecimento agropecuário todo terreno de área contínua, independentemente do tamanho ou situação (urbana ou rural), formado de uma ou mais parcelas, subordinado a um único produtor, onde se processasse uma exploração agropecuária, ou seja: o cultivo do solo com culturas permanentes e temporárias, inclusive hortaliças e flores; a criação, recriação ou engorda de animais de grande e médio porte; a criação de pequenos animais; a silvicultura ou o reflorestamento; e a extração de produtos vegetais.
} 
delimitar os estabelecimentos rurais que apresentam gestão familiar. Seu Artigo $3^{\circ}$. Diz que:

Para os efeitos desta Lei, considera-se agricultor familiar e empreendedor familiar rural aquele que pratica atividades no meio rural, atendendo, simultaneamente, aos seguintes requisitos:

I - não detenha, a qualquer título, área maior do que 4 (quatro) módulos fiscais;

II - utilize predominantemente mão-de-obra da própria família nas atividades econômicas do seu estabelecimento ou empreendimento;

III - tenha renda familiar predominantemente originada de atividades econômicas vinculadas ao próprio estabelecimento ou empreendimento;

IV - dirija seu estabelecimento ou empreendimento com sua família (p.1).

O estabelecimento familiar, de acordo com a Lei, não pode ultrapassar quatro módulos fiscais, indicando que são pequenas áreas administradas pela própria família. Por possuírem um tamanho delimitado e também por não apresentarem renda suficientemente alta, os pequenos estabelecimentos enfrentam dificuldade maior em adquirirem equipamentos e máquinas que os auxiliem de forma a serem ameaçados de absorção pelas grandes propriedades.

De acordo com a Organização das Nações Unidas para Agricultura e Alimentação (FAO) e o Instituto Nacional de Colonização e Reforma Agrária (INCRA), o universo familiar foi caracterizado pelos estabelecimentos em que a direção dos trabalhos na propriedade rural era exercida pelo produtor e o trabalho familiar superior ao trabalho contratado. A definição do universo familiar foi estabelecida a partir das condições básicas do processo de produção, como suas reações e respostas ao conjunto de variáveis externas, assim como a sua forma de apropriação da natureza (FAO/INCRA, 2000).

A agricultura familiar possui dinâmica própria na esfera produtiva, com o trabalho familiar constituindo-se na base em que vão se apoiar outros elementos da produção. A composição familiar, a relação de braços aptos para o trabalho e o consumo familiar, vão condicionar os demais fatores produtivos, como a terra e o capital, entre eles a área plantada, a base técnica, a relação com o mercado, a incorporação de assalariados, o membro da família trabalhando fora da propriedade agrícola e também a realização do trabalho não-agrícola (MENDES, 2005). 
A produção familiar também se apoia nas relações sociais, de parentesco, de solidariedade, em um universo que extrapola o econômico e o político. Logo, as relações existentes neste sistema não são baseadas somente no emprego de mão-de-obra familiar, vai muito além dessa relação de parentesco, ultrapassando as relações existentes dentro do próprio estabelecimento. As duas formas se integram numa lógica específica do conjunto familiar, compondo as diferenças econômicas e de parentesco nas necessidades de se reproduzir enquanto um conjunto de atividade familiar.

Para Lamarche (1993, p. 15), agricultura familiar é "uma unidade de produção agrícola onde trabalho e propriedade estão intimamente ligados à família”. A partir desse sentido, o conceito de agricultura familiar não pode ser confundido com as demais denominações de exploração na terra, pois cada categoria está vinculado a histórias e contextos socioeconômicos e políticos diferenciados.

Nos assentamentos rurais do município de Uberlândia (MG), a produção de alimentos é a principal fonte de renda das famílias. Dentre os produtos cultivados, podemos encontrar banana, maracujá, laranja, abacaxi, mamão, mandioca, batata doce, alface, couve, brócolis, berinjela, cheiro-verde, limão, melancia e milho verde. São hortifrutigranjeiros que os agricultores familiares produzem e comercializam, inclusive via mercados institucionais, como o PNAE e o PAA. Os agricultores familiares assentados são responsáveis por forneceram alimentos para mais de 60 mil crianças que estudam na rede municipal de ensino através do PNAE, totalizando mais de 110 toneladas de alimentos produzidos e entregues para as escolas no ano de 2015 (CORREIO DE UBERLÂNDIA, 2015).

As famílias assentadas representam grande importância na produção de alimentos no município de Uberlândia (MG), tanto por fornecerem os alimentos para o PNAE e PAA, como na comercialização nas feiras livres. Para terem maior representatividade e autonomia, eles se organizam em associações, pois assim conseguem comercializar seus produtos sem precisar de intermediários, negociam diretamente com o comprador final e, isso possibilita maior geração de renda para as famílias, melhoria na produção e agregação de valor aos seus 
produtos, além de terem a possibilidade de participarem dos mercados institucionais, que priorizam a melhoria na qualidade de vida dos agricultores familiares e estimulam o desenvolvimento rural, fazendo com que essas famílias consigam permanecer em suas propriedades.

\section{AS FAMÍLIAS ASSENTADAS DO PA DOM JOSÉ MAURO}

No assentamento Dom José Mauro encontramos famílias que fazem parte dos programas de compras institucionais, cultivando e comercializando os alimentos produzidos em suas propriedades. A participação nos programas foi uma alternativa encontrada por eles para terem um mercado consumidor de seus alimentos, possuindo garantia na venda de seus produtos e, principalmente, de que iriam receber pelos alimentos que foram vendidos. $\mathrm{O}$ mercado institucional proporcionou meios para que os agricultores familiares continuassem sua reprodução no campo, demonstrando que as políticas públicas podem ser eficazes e beneficiar vários segmentos ao mesmo tempo, desde os agricultores que cultivam os alimentos até as pessoas que consomem, proporcionando uma alimentação saudável.

Nesta primeira parte da pesquisa, ao realizar as entrevistas semiestruturadas com vinte famílias (50\% dos entrevistados), constatamos que os agricultores que fornecem os alimentos para um programa, também participam do outro, pois existe um valor máximo que cada agricultor pode receber em cada programa. O gráfico a seguir demonstra a porcentagem de agricultores familiares assentados que participam do PAA e do PNAE (figura 3). Com isso, eles planejam a produção e a entrega dos produtos para que consigam alcançar o valor permitido e receber o benefício ao longo dos meses. É interessante lembrar que o período de entrega dos alimentos coincide com o período letivo de aulas nas escolas, entre os meses de fevereiro e dezembro, o PAA também utiliza este cronograma para receber os alimentos dos agricultores familiares. 
Figura 3 - Agricultores familiares assentados que participam das compras institucionais

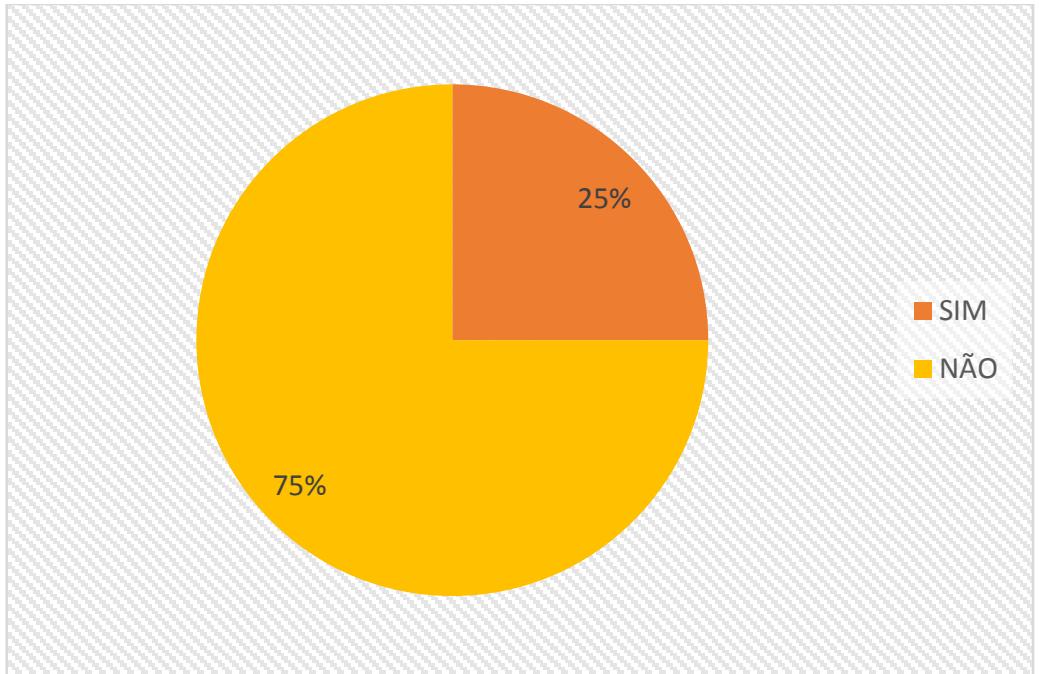

Fonte: Trabalho de Campo realizado em janeiro de 2018. Org.: GUIMARÃES, A.R., 2018.

Os agricultores familiares que participam do PAA levam os alimentos para a Central de Abastecimento da Agricultura Familiar, localizado na área urbana. Os beneficiários do programa precisam deslocar de suas propriedades até este local, pois a prefeitura não disponibiliza nenhum meio de transporte para buscar os alimentos. Este fator é uma das dificuldades encontradas pelos agricultores familiares, pois não são todos que possuem veículo para transportar a produção. A entrega dos alimentos ocorre toda quarta-feira, mas essa entrega é intercalada entre os agricultores familiares, que levam seus produtos de quinze em quinze dias. Para vender os alimentos ao programa, os agricultores precisam adquirir uma caixa de plástico para acomodar os produtos, esta caixa é uma forma de padronizar a quantidade de alimentos que estão sendo entregues, que são pesados e têm sua qualidade verificada.

Os agricultores familiares que residem no assentamento DJM cultivam diferentes tipos de alimentos (figura 4), como legumes, frutas e verduras, além da criação de animais, dentre eles os galináceos, suínos e gado leiteiro. Parte desses produtos são consumidos pelas famílias que os produzem, a outra parte é comercializada pelo PAA e PNAE e também em feiras livres (dez agricultores familiares). Os agricultores participam da "Feira da Agricultura Camponesa", que ocorre três vezes por semana, nos bairros Santa Mônica (nas segundasfeiras), Martins (quartas-feiras) e Jardim das Palmeiras (aos domingos). A 
participação nas feiras também foi um ponto que os assentados ressaltaram, pois é preciso ter veículo próprio para levar os produtos até o local da feira, alguns não possuem veículo e possuem dificuldade em comercializar seus produtos.

Figura 4 - Plantio de alimentos pelos agricultores familiares do PA Dom José Mauro em Uberlândia (MG)

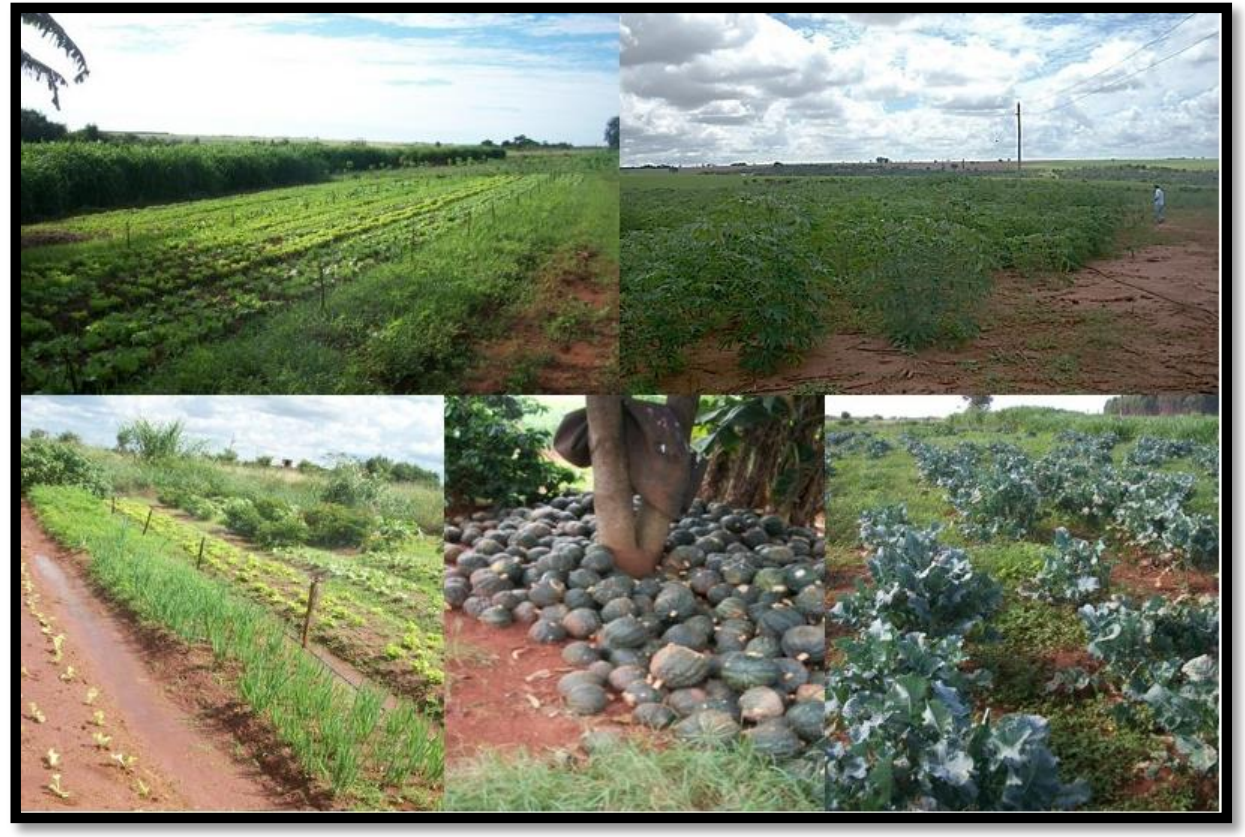

Fonte: GUIMARÃES, A. R., 2018.

Em entrevista aos agricultores familiares que participam dos programas, foi questionado se eles aumentaram a área de cultivo para entregar os alimentos ao PAA e ao PNAE, todos afirmaram que sim. Principalmente às áreas destinadas para as hortaliças, já que grande parte deles passaram a cultivar mais hortaliças somente após aderirem aos programas. Com a participação nos programas, os agricultores alegaram que passaram a ter uma produção diversificada e, o PAA em especial, tem contribuído para isso, pois ao mesmo tempo, ocorre o aumento da diversificação e a melhoria da qualidade da alimentação das famílias produtoras (DELGADO et al, 2005).

É interessante aludir o fato de que o PAA tem contribuído para reconectar a produção de alimentos ao consumo local (TRICHES; FROEHLICH, 2008), pois respeita a sazonalidade, a proximidade de mercado, a qualidade, o saber-fazer dos agricultores familiares, as relações sociais, dentre outros fatores 
relevantes. Com isso, contrapõe-se ao modelo de produção baseado nas grandes corporações, que valorizam a padronização, durabilidade dos alimentos, impessoalidade e distância dos consumidores finais, subordinando o tempo e o lugar à acumulação de capital. No PAA, sobretudo na modalidade Compra Direta com Doação Simultânea, produtores familiares e público que consome os alimentos encontram-se articulados, podendo enxergar a importância que um tem para o outro.

Ao aplicar as entrevistas, questionamos quais seriam os pontos positivos e negativos em relação ao PAA e PNAE. Como pontos positivos tem-se melhoria da renda da propriedade (100\% das respostas) e a garantia de venda da produção (100\%). Outros pontos positivos foram a diversificação da produção (80\%), melhor planejamento da propriedade (70\%), possibilidade de acesso a outros mercados (90\%), distribuição da renda durante o ano (90\%), garantia de preço (60\%), redução da dependência de intermediários (70\%). A melhoria do hábito alimentar da família foi apontada por $60 \%$ dos agricultores entrevistados. Também foram apontados como pontos positivos pelos agricultores a melhoria da qualidade dos alimentos nas escolas e a garantia da continuidade do agricultor no campo.

Mas os agricultores familiares também elencaram alguns pontos negativos sobre os programas, o mais apontado por eles foi o valor baixo liberado por agricultor/DAP (100\% das respostas). A logística de entrega dos alimentos também foi um ponto ressaltado (70\%), pois nem todos possuem veículo próprio para transportar seus produtos, 50\% afirmaram que acham burocrático para ser beneficiário do programa, 20\% enxergaram como ponto negativo a não sintonia entre o calendário dos programas e a produção, e 40\% relataram sobre a assistência técnica prestada pela prefeitura, afirmando que o número de técnicos responsáveis pela assistência é insuficiente para atender todos agricultores do município, ocorrendo uma demora nos atendimentos.

O principal ponto negativo dos programas apontado pelos entrevistados, é o valor liberado por agricultor, mas $90 \%$ dos agricultores entrevistados declaram que o preço pago pelos produtos é suficiente para cobrir os custos de produção, $70 \%$ dos agricultores dizem que o valor total recebido por ano é 
suficiente para a melhoria na renda da propriedade, realizando algum tipo de investimento na propriedade através de recursos próprios.

Na questão sobre a continuidade do PAA e PNAE, 100\% dos agricultores entrevistados disseram que a existência dos programas é importante para a permanência deles no campo, mas apontaram sugestões de melhoria. As principais sugestões foram, o aumento do valor limite por agricultor fornecedor beneficiário e dos preços dos produtos para aumentar o retorno financeiro da atividade produtiva.

Ao serem indagados sobre a hipótese de interrupção do PAA e do PNAE, todos os agricultores familiares entrevistados declararam que haverá reflexos no sistema produtivo. Sendo os maiores impactos a diminuição da renda, a redução da produção dos produtos entregues e a comercialização dos produtos em outros mercados.

Em relação à execução do PNAE, foi colocada a necessidade de maior rigor do Ministério da Educação para cumprimento da legislação pelas prefeituras municipais de no mínimo 30\% da compra dos produtos para alimentação escolar seja da agricultura familiar, pois o município de Uberlândia ainda não conseguiu alcançar a porcentagem mínima proposta lei.

Com os dados parciais obtidos na pesquisa, observa-se que o PAA e o PNAE buscam distribuir renda, injetar dinheiro na economia local, incentivar a produção agrícola de transição agroecológica, tendo a possibilidade de proporcionar alimentos de boa qualidade a população local. Com a comercialização de seus produtos, sejam pelas feiras livres, pelo PAA ou PNAE, os agricultores familiares assentados encontraram estratégias para permanecerem no campo, pois o dia-a-dia na terra não é fácil, eles lidam com dificuldades diariamente, principalmente para gerar renda e continuarem sua reprodução no campo.

Assim, além de enfrentarem os desafios para permanecerem em suas terras, os agricultores familiares também lidam com outros obstáculos para aumentar a renda mensal, como o valor pago pelos alimentos produzidos e comercializados por eles. 


\section{CONSIDERAÇÕES FINAIS}

Na presente pesquisa, a preocupação central foi avaliar e diagnosticar os efeitos do PAA e do PNAE na vida das famílias assentadas que aderiram aos programas, com intuito de verificar se os mercados institucionais contribuem para a permanência das famílias no meio rural e na melhoria da qualidade de vida dos agricultores familiares.

No assentamento rural Dom José Mauro é possível encontrar famílias que praticam diferentes atividades para continuarem na terra, desenvolvendo atividades ligadas ao cultivo de alimentos, pecuária leiteira e também prestando serviços fora de sua propriedade, além de algumas famílias que participam dos mercados institucionais. Essas atividades constituem formas encontradas para gerar renda nos estabelecimentos, plantando, produzindo, cultivando e comercializando produtos.

É neste sentido que o assentamento passa pela construção de novos territórios, sendo um território de luta, de conquistas, de territorialização, isto é, pela capacidade que os sujeitos locais possuem para manejar e valorizar os produtos específicos de onde residem. A participação em mercados institucionais também constitui uma forma de diversificar a renda dos agricultores familiares, estimulando-os a produzirem alimentos saudáveis e, como consequência, melhorando os hábitos alimentares das pessoas que compõem a família. Tanto o PAA quanto PNAE são programas que visam o fortalecimento e valorização das famílias que vivem no campo. A partir da participação nestes programas, os agricultores familiares têm a possibilidade de incrementar sua renda mensal, sendo uma estratégia desenvolvida por eles para garantir sua reprodução no campo.

A partir da aplicação de entrevistas semiestruturadas para vinte famílias assentadas, constatamos que os agricultores familiares que aderiram aos programas (5 famílias) possuem estabilidade financeira melhor do que as famílias que não participam dos programas, pois estas famílias têm a garantia de que receberão pelos produtos vendidos, havendo a possibilidade de planejar novos investimentos para a propriedade. As famílias que não participam dos programas lidam com as incertezas do mercado convencional, pois nem sempre 
eles conseguem comercializar seus produtos e, ainda há a incerteza de que podem não receber por eles.

Tanto o PAA quanto o PNAE são políticas públicas voltadas para o fortalecimento dos agricultores familiares e, no assentamento Dom José Mauro verificamos que estes dois programas são fundamentais para o desenvolvimento das famílias assentadas. Mas, infelizmente não são todas as famílias que fornecem alimentos aos programas, sendo visível a diferença nas propriedades que participam das propriedades que não participam, como a estrutura da casa, a aquisição de veículo próprio, a compra de equipamentos para auxiliar na produção dos produtos, dentre outras benfeitorias que os agricultores familiares realizaram somente após serem beneficiários dos programas.

Com isso, a partir das reflexões realizadas, podemos verificar que as famílias assentadas encontraram nos mercados institucionais uma forma de permanecerem em suas terras, pois eles possuem uma garantia de que receberão o valor dos produtos que foram vendidos, podendo fazer planos para investir em suas propriedades, agregando valor aos produtos e obtendo uma maior geração de renda.

\section{REFERÊNCIAS}

BRASIL. Lei no 11.326, de 24 de julho de 2oo6. Estabelece as diretrizes para a formulação da Política Nacional da Agricultura Familiar e Empreendimentos Familiares Rurais. Disponível em: http://www.planalto.gov. br/ccivil_03/_ato2004-2006/2006/lei/l11326.htm. Acesso em: 10 abr. 2017.

BRASIL. Lei n. ${ }^{\circ} 11.947$, de 16 de junho de 2oog. Dispõe sobre o atendimento da alimentação escolar e do Programa Dinheiro Direto na Escola aos alunos da educação básica. [2009]. Disponível em: http://www.planalto.go v.br/ccivil_03/_ato2007-2010/2009/lei/l11947.htm. Acesso em: 18 out. 2017.

BRASIL. Lei no. 12.512, de 14 de outubro de 2011. Institui o Programa de Apoio à Conservação Ambiental e o Programa de Fomento às Atividades Produtivas Rurais. Disponível em: http://www.planalto.gov.br/ccivil_03/_ato2 011-2014/2011/lei/l12512.htm. Acesso em: 24 jun. 2018.

\section{CATÁLAGO de Programas do Governo Federal destinados aos}

Municípios. 2008. Disponível em: http://www.ibam.org.br/media/arquivos/e studos/cat\%C3\%A1logo_de_programas_do_governo_federal_o1dezo8.pdf. Acesso em: 10 out. 2017. 
CORREIO DE UBERLÂNDIA. Produção de assentamentos mais que dobra em relação a 2013. Também disponível em: http://www.correiodeube rlandia.com.br/cidade-e-regiao/producao-de-assentamentos-mais-que-dobraem-relacao-a-2013/. Acesso em: 10 maio 2017.

DELGADO, Guilherme Costa; CONCEIÇÃO, Júnia Cristina P. R. da; OLIVEIRA, Jader José de. Avaliação do programa de aquisição de alimentos da agricultura familiar. Brasília: IPEA, 2005. Disponível em: http://www.ipea.g ov.br/portal/images/stories/PDFs/TDs/td_1145.pdf. Acesso em: 03 jul. 2018.

FAO/INCRA. Novo retrato da agricultura familiar: o Brasil Redescoberto. Projeto de cooperação técnica. Brasília. 2000. Também disponível em: http://www.deser.org.br/biblioteca_read.asp?id=3. Acesso em: 08 abr. 2017.

IBGE - Instituto Brasileiro de Geografia e Estatística. Censos Agropecuários. Disponível em: http://www.ibge.gov.br, 2017. Acesso em: 10 abr. 2017.

IBGE - Instituto Brasileiro de Geografia e Estatística. Censos Agropecuários. Disponível em: https://ww2.ibge.gov.br/home/estatistica/economia/agropecua ria/censoagro/default.shtm. Acesso em: 10 abr. 2018.

INCRA - Instituto Nacional de Colonização e Reforma Agrária, 2017. Disponível em: http//www.incra.gov.br. Acesso em: 10 abr. 2017.

LAMARCHE, Hugues (Coord.). Agricultura familiar: do mito à realidade. Tradução de Jehovanira C. de Souza. Campinas/SP: Ed: UNICAMP, 1993.

MENDES, Estevane de Paula P. A produção rural familiar em Goiás: as comunidades rurais no município de Catalão. 296 f. Tese (Doutorado em Geografia) - Faculdade de Ciências e Tecnologia, Universidade Estadual Paulista, Presidente Prudente, 2005.

TEIXEIRA, Elenaldo Celso. O papel das políticas públicas no desenvolvimento local e na transformação da realidade. Revista Políticas Públicas, Salvador, v.2 n.1 p. 1-11. 2002 - AATR (Associação de Advogados de Trabalhadores Rurais da Bahia). Bahia, 2002. Disponível em: http://www.escoladebicicleta.com.br/p oliticaspublicas.pdf. Acesso em: $10 \mathrm{abr} .2018$.

TRICHES, Rozane Márcia; FROEHLICH, Elisangela. Reconectando o consumo à produção: a aquisição de produtos da agricultura familiar para a alimentação escolar. In: II Colóquio Agricultura Familiar e Desenvolvimento Rural. Porto Alegre: PGDR, 2008.

WANDERLEY, Maria de Nazareth Baudel. Raízes históricas do campesinato brasileiro. In: TEDESCO, João Carlos (Org.). Agricultura familiar: realidades e perspectivas. $3^{\circ}$ ed. Passo Fundo: UPF, 2001. p. 21-56. 